\title{
Disaster Curricula in Medical and Health Care Education: Adopting an Interprofessional Approach
}

\author{
Ashton Barnett-Vanes, BSc; ${ }^{1}$ Ramon Lorenzo Luis Guinto, MD $^{2}$
}

1. Faculty of Medicine, Imperial College London, United Kingdom

2. College of Medicine, University of the Philippines Manila, Philippines

\author{
Correspondence: \\ Ashton Barnett-Vanes \\ Sir Alexander Fleming Building \\ Imperial College London \\ South Kensington Campus \\ London SW7 2AZ \\ E-mail: ashton.barnett-vanes11@imperial.ac.uk
}

Received: May 18, 2013

Accepted: July 2, 2013

doi:10.1017/S1049023X13009114
Disasters continue to pose substantial threats to human health worldwide. Knowledge in the principles of disaster medicine and of the wider function of the health system is therefore essential for health care teams who must respond effectively in dynamic environments with strained resources.

Developed in 2005 by the United Nations International Strategy for Disaster Reduction, the Hyogo Framework for Action acknowledged the importance of "knowledge, innovation and education" to help build disaster resilience, emphasizing the need for individuals to be "well prepared and ready to act."

Strengthening the preparedness of health systems to support disaster-affected communities could start in university, with educational strategies aimed at medical and health care students. Despite increasing international attention, current disaster curricula coverage levels during undergraduate pre-license training appear alarmingly low. ${ }^{2-4}$ Moreover, little consideration has been given to collaborative learning among medical and other health care students, which is vital if we are to "successfully mitigate the effects of disasters."

Interprofessional collaboration is the foundation of effective health care teams. Barriers to this, such as difficulties over leadership, uncertainty, negotiation, and conflict resolution, are exacerbated in the disaster setting. ${ }^{6}$ Interprofessional disaster education could therefore strengthen non-technical skills needed to overcome these barriers early, ${ }^{7}$ and prevent imbalances in the educational experiences and competencies of different medical and health care students in disaster medicine. Thus far, educational efforts "have been limited primarily to individual specialties"; defragmentation of these programs could enable a holistic interprofessional approach. Furthermore, disasters demand unique interprofessional collaboration between health care professionals and other services in these settings, particularly among specialist units such as Disaster Medical Assistance Teams. ${ }^{9}$

The importance of preparing future health care practitioners for disasters, together with the interprofessional challenges disaster situations pose, suggests that research on interprofessional disaster education programs is warranted. Despite the existence of small-scale pilot initiatives, which demonstrate the potential to establish strong interprofessional skills among health care students in the context of disasters, ${ }^{10}$ the evidence base on this subject remains limited and must be strengthened. This could be achieved by expanding on previous initiatives, towards large-scale, multi-institute pilot programs, with standardized curricula and outcome measures.

Student representative organizations have expressed their desire to enhance disaster education for medical and health care students. For example, the International Federation of Medical Students, an international body representing over 1 million medical students worldwide, produced a policy statement in 2012 calling on medical schools to "incorporate disaster medicine and health emergency management into the medical curricula" and the health sector to "provide training of medical students and other health care professionals in disaster medicine and health emergency management."11 Furthermore, another organization, Asian Medical Students' Association-International, chose disaster medicine as the theme of its 2012 conference.

Further progress will need agreement among educationalists on disaster curricula content and strategies for implementation. Dialogue among these stakeholders also should involve disaster organizations and student representatives. Together with input from national and international interprofessional organizations, appropriate development and integration of interprofessional disaster education into mainstream medical and health care curricula could be achieved. Interprofessional organizations could ensure 
programs utilize the most appropriate practices in interprofessional education for dealing with disasters. ${ }^{12}$ For example, incorporation of technical training and simulation exercises, such as high-fidelity manikins to facilitate competency-based assessment of students in emergency scenarios, would develop practical skills alongside those related to communication and leadership.

Finally, global leadership in disaster medicine education is required. The publication of the World Health Organization guideline on integrating emergency preparedness and response education into undergraduate nursing curricula ${ }^{13}$ provided nursing bodies

\section{References}

1. Education UNISDR Website 2012. http://www.unisdr.org/we/advocate/education. Accessed May 17, 2013.

2. Smith J, Levy MJ, Hsu EB, Lee Levy J. Disaster curricula in medical education: pilot survey. Prehosp Disaster Med. 2012;27(5):492-494.

3. Kaiser HE, Barnett DJ, Hsu EB, Kirsch TD, James JJ, Subbarao I. Perspectives of future physicians on disaster medicine and public health preparedness: challenges of building a capable and sustainable auxiliary medical workforce. Disaster Med Public Health Prep. 2009;3(4):210-216.

4. Scott LA, Carson DS, Greenwell IB. Disaster 101: a novel approach to disaster medicine training for health professionals. J Emerg Med. 2010;39(2):220-226.

5. Parrillo S, Perper A, Christensen D, Glassman ES. A holistic approach to disaster medical education. Prehosp Disaster Med. 2013;28(3):1-2.

6. Larkin GL. Unwitting partners in death-the ethics of teamwork in disaster management. Virtual Mentor. 2010;12(6):495-501.

7. Willems A, Waxman B, Bacon AK, Smith J, Peller J, Kitto S. Interprofessional non-technical skills for surgeons in disaster response: a qualitative study of the Australian perspective. J Interprof Care. 2013;27(2):177-183. worldwide with a framework to facilitate program design and implementation. Such guidance is welcomed and more is needed.

The approaching post-Hyogo era provides a timely platform to recognize disaster curricula in medical and health care education as an integral component for strengthening the preparedness of health systems to future disasters. Ensuring this education adopts an interprofessional approach could equip the next generation of medical and health care professionals with skills for responding effectively as a team when disaster strikes, and could lead to crossdisciplinary advancements in the field of disaster medicine.

8. Subbarao I, Lyznicki JM, Hsu EB, et al. A consensus-based educational framework and competency set for the discipline of disaster medicine and public health preparedness. Disaster Med Public Health Prep. 2008;2(1):57-68.

9. Fuse A, Yokota H. An analysis of Japan Disaster Medical Assistance Team (J-DMAT) deployments in comparison with those of J-DMAT's counterpart in the United States (US-DMAT). J Nippon Med Sch. 2010;77(6):318-324.

10. Mackintosh S, Mcclure D. Interprofessional education as a vehicle to instill teamwork mentality for disaster preparedness and response in health care professional students. Prehosp Disaster Med. 2011;26(Supplement S1):s45.

11. IFMSA. IFMSA Policy Statement on Disasters and Emergencies 2012. http://imccam 2012.files.wordpress.com/2012/07/ps-am12-disasters-and-emergencies.pdf. Accessed May 17, 2013.

12. Barr H. Universities respond together to the interprofessional challenge in Japan. J Interprof Care. 2012;26(5):350-352.

13. World Health Organisation. Integrating emergency preparedness and response into undergraduate nursing curricula 2008. http://whqlibdoc.who.int/hq/2008/WHO HAC_BRO_08.7_eng.pdf. Accessed May 17, 2013. 